\title{
TECNOLOGIA NO ENSINO DE GEOGRAFIA: UMA REFLEXÃO ACERCA DO USO DO APLICATIVO "LANDSCAPAR" NO ENSINO-APRENDIZAGEM DE CURVAS DE NÍVEL
}

\author{
João Paulo Morandi Barboza \\ Secretaria de Educação do Estado de São Paulo (SEE/SP) \\ joaomorandi@prof.educacao.sp.gov.br
}

Carina Alexandra Rondini

Universidade Estadual Paulista (UNESP), Instituto de Biociências, Letras e Ciências Exatas (IBILCE), PósGraduação em Ensino e Processos Formativos, São José do Rio Preto, SP, Brasil carina.rondini@unesp.br

\begin{abstract}
RESUMO
O estudo da cartografia ocorre em diferentes etapas da vida estudantil, durante o Ensino Fundamental II e o Ensino Médio, e uma de suas ramificações se pauta na compreensão do conceito de curvas de nível no relevo. Buscando contextualizar esse momento de estudo, enfrentar os desafios de um ensino-aprendizagem dinâmico e significativo, além de agregar o uso de tecnologias de informação, o aplicativo LandscapAR se apresenta como um instrumento coerente para tal finalidade. Levando-se em consideração que os estudantes participantes deste estudo podem ser classificados como nativos digitais, o uso dessa tecnologia possibilitou desenvolver uma atividade lúdico-científica com alunos do sétimo ano do Ensino Fundamental II, estabelecendo um diálogo entre o conceito de curvas de nível e outros conceitos primordiais da cartografia, como o título, a legenda, a orientação e a escala. Agindo como um professor-tutor, orientando os alunos em como utilizar o aplicativo para a atividade de estudo, chegou-se à conclusão de que a tecnologia, quando usada de maneira correta, com conhecimento dos recursos oferecidos e inserida em um plano de estudos, torna-se uma grande aliada na busca da efetividade do processo ensinoaprendizagem.
\end{abstract}

Palavras-chave: Cartografia. Relevo. Recursos Tecnológicos. Sala de Aula Comum.

\section{TECHNOLOGY IN TEACHING OF GEOGRAPHY: A REFLECTION ABOUT THE USE OF THE LANDSCAPAR APPLICATION IN TEACHING-LEARNING CONTOUR LINES}

\begin{abstract}
The study of cartography occurs at different stages of student life during middle school and high school, and one of its ramifications is based on the understanding of the concept of contour lines on relief. Seeking to contextualize this moment of study, to face the challenges of a dynamic and meaningful teaching-learning process, besides adding the use of information technologies, the LandscapAR application presents itself as a coherent instrument for this purpose. Taking into account that the students participating in this study can be classified as digital natives, the use of this technology made it possible to develop a playful-scientific activity with students from the seventh grade of middle school, establishing a dialogue between the concept of contour lines and other primordial concepts of cartography, such as title, legend, orientation and scale. Acting as a mentor-teacher, guiding students on how to use the application for the study activity it was concluded that technology, when used correctly, with knowledge of the resources offered, and inserted in a study plan, becomes of great importance in the search the effectiveness of the teachinglearning process.
\end{abstract}

Keywords: Cartography. Relief. Thechnological Resources. Common Classroom.

\section{INTRODUÇÃO}

Com o advento do período conhecido como "renovação da geografia" no Brasil, a partir dos anos de 1970/1980, novos temas foram incorporados às pesquisas e debates relacionados à construção do saber geográfico, procurando conferir uma prática comprometida com a transformação social e voltada para compreender as contradições inerentes ao espaço geográfico. 
Essa renovação iminente na ciência geográfica conduz naturalmente o processo de ensino-aprendizagem da geografia a novos métodos, frente ao tradicionalismo. Nos dias atuais, os estudantes estão cada vez mais entretidos com a tecnologia, o que afeta sua personalidade e estilo de vida. Em face dessa realidade, o professor precisa procurar intervir com novas ferramentas para o ensino em sala de aula, envolvendo o estudante e buscando fazer com que haja prazer no estudo. Em relação à ressignificação do ensino atrelado a novas tecnologias, Almeida (2002) afirma:

\begin{abstract}
O momento requer uma nova forma de pensar e agir para lidar com a rapidez e a abrangência de informações com o dinamismo do conhecimento. Evidencia-se uma nova organização de tempo e espaço e uma grande diversidade de situações que exigem um posicionamento crítico e reflexivo do indivíduo para fazer suas escolhas e definir suas prioridades. Além disso, há o elemento inusitado com o qual nos deparamos nas várias situações do cotidiano, demandando o desenvolvimento de estratégias criativas e de novas aprendizagens. (ALMEIDA, 2002, p. 6).
\end{abstract}

A busca por recursos diversos de ensino, por uma nova forma de pensar e agir, no âmbito educacional, diante do dinamismo do conhecimento e do desenvolvimento de estratégias criativas e de novas aprendizagens faz-se mais do que latente no cenário educacional contemporâneo, uma vez que o tradicionalismo da instituição escolar pede passagem aos novos meios de comunicação e às novas tecnologias. Nesse sentido, Vesentini defende:

O ensino tradicional da geografia - mnemônico e descritivo, alicerçado no esquema "a Terra e o Homem" - não tem lugar na escola do século XXI. Ou a geografia muda radicalmente e mostra que pode contribuir para formar cidadãos ativos, para levar 0 educando a compreender o mundo em que vivemos, para ajudá-lo a entender as relações problemáticas entre sociedade e natureza e entre todas as escalas geográficas, ou ela vai acabar virando peça de museu. (VESENTINI, 2004, p. 220).

Em vista desse contexto e da necessidade de encontrar meios e métodos que possam colaborar com o processo ensino-aprendizagem, nos moldes atuais, ao menos nos desejados, buscamos conceitos relacionados aos chamados "Perfis Digitais", em Cassany (2017), procurando compreender de uma melhor maneira o alunado contemporâneo.

\title{
NATIVOS, IMIGRANTES, VISITANTES OU RESIDENTES VIRTUAIS? QUE GERAÇÃO É ESSA?
}

Daniel Cassany, escritor, professor e pesquisador espanhol, oferece-nos uma reflexão quanto aos perfis digitais, ao nos pôr em contato com diferentes autores que procuram definir qual seria a melhor classificação para as antigas, atuais e futuras gerações de pessoas que se envolvem com a tecnologia, em qualquer que seja a esfera analisada, inclusive no contexto educacional.

Ao apresentar Prensky (2001), Cassany (2017) traz a primeira perspectiva, trabalhando os conceitos de "nativos" e "imigrantes" digitais e, em contrapartida, busca em White e Cornu (2011) uma segunda perspectiva e um contraponto à discussão, diante da teoria desses autores, que afirmam existirem os "visitantes" e os "residentes" digitais.

Na formulação do conceito, Prensky (2001) parte da premissa de que existem dois grupos de usuários dos recursos digitais: um primeiro grupo contempla características relacionadas a aspectos tradicionais de escrita e aprendizagem, enquanto um segundo grupo perpassa uma perspectiva com maior interação e domínio dos instrumentos e da linguagem digital.

O conceito de "nativos" e "imigrantes" digitais é exposto por Prensky (2001), considerando-se o "nativo digital" aquele que nasceu a partir do ano de 1993, época em que a internet se torna acessível, apesar de restrita, a uma parte da população mundial, enquanto o "imigrante digital" é aquele nascido anteriormente a esse período.

O referido autor procura contextualizar as diferenças entre os dois grupos propostos, a partir de suas práticas, características psicológicas e interesses. Porém, White e Cornu (2011), ao trabalharem os conceitos de "visitantes" e "residentes" digitais, atentam para o fato de que um chamado "imigrante digital" pode ser mais perito do que um "nativo digital" e, devido a essa concepção, confrontam esses conceitos.

Assim, White e Cornu (2011) discordam da classificação de Prensky (2001) e fazem a sua classificação atrelada mais às práticas do usuário digital do que aos aspectos associados aos interesses ou características pessoais. 
Seguindo a classificação de White e Cornu (2011), o professor Cassany (2017) nos remete à reflexão de que a geração de estudantes dos dias atuais seria constituída, em quase sua completude, dos chamados "residentes digitais", os quais, apesar do domínio dos recursos por parte desses estudantes, é necessário que o professor obtenha o conhecimento necessário para poder mediar a relação do estudante com o meio digital de aprendizagem e possibilitar que essa apropriação permita a construção de um sujeito cada vez mais crítico e capaz de elaborar níveis de compreensão mais substanciais.

$\mathrm{Na}$ geografia, assuntos relacionados aos aspectos físicos do planeta encontram maior resistência e dificuldade de compreensão e análise por parte do corpo discente, principalmente quando se leva em conta o seu aspecto descritivo, enciclopedista, de memorização e até abstrato, herdado, de certa maneira, das características da geografia tradicional, reforçada no discurso nacionalista que inflava os conteúdos geográficos militares e ecoava sobre a geografia escolar. Quanto à predileção aos conteúdos da geografia física, nos parâmetros da geografia moderna, moldadas ao discurso nacionalista, Brabant (2017) esclarece:

Essa predileção da geografia escolar pela geografia física encontra também suas raízes na geografia dos militares. O militar conduz seu raciocínio estratégico a partir dos dados topográficos. São estes dados, no seu aspecto descritivo, que foram repetidos pela geografia escolar. (BRABANT, 2017, p. 18).

É possível notar que a geografia escolar, ao adotar a perspectiva da geografia militar, trilhou um caminho que a tornou essencialmente abstrata, descritiva, dificultando sua compreensão a partir da vivência e do cotidiano de grande gama de alunos. Brabant ainda destaca que a formação de novos professores passa por um enciclopedismo acadêmico, o qual se tornou característica do discurso geográfico dos professores, refletindo diretamente para o tédio que assola as novas gerações de alunos, ao estudar assuntos da ciência geográfica:

Professores de geografia formam outros professores que por sua vez continuam o círculo. A geografia universitária desembocando quase unicamente na geografia escolar, vai deste modo moldá-la a sua imagem, abarrotá-la de conhecimentos "indispensáveis", completá-la até a apoplexia. [...] O enciclopedismo contribuiu para a abstração crescente do discurso geográfico, ao mesmo tempo em que alimentou o tédio das gerações de alunos que classificaram a geografia entre as matérias a memorizar. (BRABANT, 2017, p. 19).

Nessa direção, insere-se o estudo de "curvas de nível", cuja apreensão, embora encontre barreiras por parte dos estudantes, apresenta-se como um conteúdo que possibilita a realização de atividades em meio digital, aproximando-se da geração intitulada "residentes digitais", no sentido de conduzir a um processo de ensino-aprendizagem mais eficaz.

A partir dessa reflexão acerca de novos métodos e dos anseios e práticas digitais dos estudantes atuais, procuramos relatar e analisar os resultados de uma experiência em sala de aula, abordando o ensino do conceito de curvas de nível e utilizando, para tanto, um aplicativo que adota a tecnologia de realidade aumentada, de maneira lúdica e complementar ao conteúdo didático.

\section{CURRÍCULO, CARTOGRAFIA E CURVAS DE NÍVEL}

O currículo base oficial do Estado de São Paulo para os anos iniciais e anos finais do Ensino Fundamental e Ensino Médio, desenvolvido no ano de 2008, pela Secretaria da Educação do Estado de São Paulo, traz, em seu texto dedicado às ciências humanas, mais especificamente nas páginas direcionadas à ciência geográfica, a orientação para que se desenvolva o estudo da educação cartográfica.

Nas páginas 78 e 79 do referido documento, fica clara a importância da alfabetização cartográfica para a formação da cidadania. Em consonância, verifica-se ainda que a aprendizagem de geografia deva ser entendida como um processo de construção da espacialidade, considerando, dentre outros objetivos, a habilidade de elaborar, ler e interpretar mapas e cartas, como se pode observar no trecho a seguir:

Educação cartográfica: a alfabetização cartográfica deve ser entendida como um dos instrumentos indispensáveis para a formação da cidadania. Como afirma Yves Lacoste (2009), "cartas, para quem não aprendeu a lê-las e utilizá-las, sem dúvida, não têm qualquer sentido, como não teria uma página escrita para quem não aprendeu a ler". Portanto, uma educação que objetive a formação do cidadão consciente e autônomo deve incorporar no currículo os fundamentos da alfabetização cartográfica. Dessa forma, a aprendizagem da Geografia na educação básica, entendida como um processo de construção da espacialidade, deve considerar os seguintes objetivos [...] Elaborar, ler e interpretar mapas e cartas. (SÃO PAULO, 2012, p. 78-79).

$\begin{array}{lllll}\text { Caminhos de Geografia } \quad \text { Uberlândia-MG } & \text { v. 22, n. } 79 & \text { Fev/2020 } & \text { p. 39-55 Página } 41\end{array}$


Ao analisar as páginas 83 a 98 do documento, encontramos o "Quadro de conteúdos e habilidades de Geografia”, com a indicação do conteúdo que deve ser trabalhado com os estudantes do Ensino Fundamental II.

Dessa maneira, percebemos que, no sexto ano do referido nível, mais precisamente no segundo bimestre, fazem parte do conteúdo os estudos sobre a linguagem dos mapas, orientação relativa (rosa dos ventos), atributos dos mapas, dentre outros ligados à cartografia, sendo que as habilidades a serem desenvolvidas se pautam em identificar os pontos cardeais e colaterais e aplicar técnicas de orientação relativa, reconhecer a diferença entre escala gráfica e numérica, inferir título mais adequado para uma representação cartográfica e reconhecer o significado da legenda para a representação dos fenômenos geográficos.

\section{CARTOGRAFIA}

Cartografia, como conceito, foi estabelecido pela Associação Cartográfica Internacional (ACl), no ano de 1966, sendo ratificado pela Organização das Nações Unidas para a Educação, a Ciência e a Cultura (UNESCO), no mesmo ano. Essa definição pode ser encontrada no site do Instituto Brasileiro de Geografia e Estatística (IBGE):

A Cartografia apresenta-se como o conjunto de estudos e operações científicas, técnicas e artísticas que, tendo por base os resultados de observações diretas ou da análise de documentação, se voltam para a elaboração de mapas, cartas e outras formas de expressão ou representação de objetos, elementos, fenômenos e ambientes físicos e socioeconômicos, bem como a sua utilização. (IBGE, 1999:12).

Interessante observar que o conceito tradicional, trazido na citação anterior, remete-nos à cartografia em três diferentes aspectos: uma ciência, uma técnica e uma arte.

É considerada uma ciência, já que, para a confecção de um mapa ou qualquer outro produto cartográfico, como cartas náuticas, plantas, croquis etc., é necessária uma série de conhecimentos científicos, como, por exemplo, levantamento e análise de dados estatísticos, conhecimento das diferentes realidades socioeconômicas representadas, análise territorial, conhecimento de conceitos geográficos, geológicos, dentre vários outros fatores que variam conforme o objetivo final do produto.

Ao tratar a cartografia como uma operação técnica, tem-se em conta o conjunto de procedimentos que englobam a produção cartográfica. A maneira de se realizarem as projeções, por exemplo, baseadas em técnicas de projeção cilíndrica, cônica, azimutal, exemplifica esse caráter da cartografia.

Por fim, ao relacionar a cartografia com uma arte, deve-se levar em conta que a utilização da paleta de cores e texturas no procedimento cartográfico não é em vão, possuindo significados que determinam a linguagem do produto final. Vale lembrar que, em muitas das primeiras cartas náuticas, ou de descrição dos "novos mundos" descobertos no período das grandes navegações, o uso de iluminuras era recorrente na cartografia, na maioria das vezes, como forma de comunicar algum tipo de perigo ou de ilustrar algo desconhecido ou de que a ciência da época não possuía compreensão.

Atualmente, o conceito de cartografia apresenta uma acentuada tendência de alterar seu significado inicial, remodelando-se o conceito e agregando-se os novos instrumentos tecnológicos disponíveis para a sua produção. Algumas definições incluem os aspectos da confecção e uso de mapas, cartas e outros produtos, como, por exemplo, as visualizações 3D da superfície. Outras entendem a cartografia como o conjunto das ciências que conduzem ao mapa.

Assim, sendo certo que a cartografia, uma ciência secular, se faz presente no currículo estudantil, acaba por acompanhar o estudante por toda a fase escolar e, no sétimo ano do Ensino Fundamental II, é requisito ao aprofundar-se nos estudos sobre o território brasileiro, regionalização, domínios naturais, dentre outros. Diante desse contexto, mostra-se de fundamental importância a compreensão dos conceitos básicos da cartografia para que, junto à geografia, os estudantes desenvolvam uma aprendizagem cartográfica e um saber geográfico. Nesse sentido, Oliveira (2009) comenta:

É notável a relação existente entre a cartografia e a produção de um saber geográfico ao longo da história, não apenas, a cartografia como ferramenta da geografia para expressar os conhecimentos geográficos, mas, as representações cartográficas como expressão e mesmo fonte de análise dos contextos sob os quais se dava a produção de um conhecimento em geografia. (OLIVEIRA, 2009, p. 9). 
A cartografia, assim como as demais ciências, prosperou com os avanços tecnológicos disponíveis, alcançando resultados mais precisos e tornando a leitura dos espaços mapeados mais completa. Sousa et al. (2009) refletem sobre a significativa evolução da ciência cartográfica:

Com o acelerado processo de evolução tecnológica, as técnicas usadas para produção das informações cartográficas foram substancialmente transformadas. Hoje, o uso de satélites, proporcionando a captação em segundos ou milésimos de segundo do espaço e, sobretudo, a utilização de softwares criando Sistemas de Informação Geográfica - SIG revolucionam as geotecnologias da informação. (SOUSA et al., 2009, p. 3).

O trecho supracitado permite a reflexão sobre o avanço dos meios tecnológicos, na obtenção de dados e imagens que vão compor, de maneira mais completa e exata, os produtos cartográficos mais recentes, porém, essa tecnologia avançada conquista um alcance tímido, em meio ao ambiente escolar. A cartografia escolar se apoia em imagens, cartas e mapas disponibilizados, na maioria das vezes, no livro didático e na transposição do conhecimento avalizado pelo professor. Dessa forma, surge a indagação de como a cartografia escolar deve ser trabalhada, diante os alunos.

Uma das grandes preocupações que permeiam a didática cartográfica é de que maneira a figura do professor promove a passagem do saber "universitário", adquirido em sua formação acadêmica, para o saber "ensinado nas escolas". Simielli enfatiza:

Transformar o saber universitário, sem desfigurá-lo e sem desvalorizá-lo, em objeto de ensino supõe uma transposição didática que nem vulgarize nem empobreça o saber universitário, mas que se apresente como uma construção diferenciada, realizada com a intenção de atender o público escolar [...] Mais do que uma transposição didática, tratase de uma verdadeira reconstrução do saber geográfico sobre bases parcialmente diferentes, porque as finalidades, os objetivos e os meios da prática de geografia não são os mesmos na universidade e no ensino fundamental e médio. (SIMIELLI, 2010, p. 9293).

A cartografia escolar, portanto, diferencia-se da cartografia científica/universitária, utilizada por profissionais ou debatida no meio acadêmico, distinguindo-se entre si no próprio seio estudantil, ao passo que seu ensino e sua compreensão devem atender às demandas e necessidades de cada aluno/série, observada a diferenciação entre os níveis do Ensino Fundamental I e ll e do Ensino Médio.

Durante o desenvolvimento dos temas relacionados à cartografia com os estudantes do Ensino Fundamental II, mais precisamente no sexto e sétimo anos, chamou-nos a atenção o fato de que as representações do relevo, por meio de cartas topográficas, pouco eram citadas nos materiais disponíveis, muitas vezes nem mesmo sendo trabalhadas em sala de aula. A cartografia escolar, em todas as suas vertentes, não só no caso das cartas topográficas, por vezes, vem despida de seu material principal.

A correlação entre o ensino de geografia e o emprego dos mapas, em sala de aula, continua a permear o imaginário de quem não atenta à realidade escolar, pois, cada vez mais, o uso das cartas se torna escasso. Katuta e Souza (2001, p. 121), ao se referirem ao uso dos mapas na sala de aula, são enfáticos ao afirmarem que, "na maioria das vezes impera um certo abandono, descaso e subutilização desse meio de comunicação em razão de um discurso tido como geográfico, mas que na verdade empobrece o papel da escola e da própria disciplina em questão".

O não uso da linguagem cartográfica, durante as aulas, prejudica a alfabetização cartográfica do aluno e o impossibilita de um desenvolvimento mais amplo dentro dos conceitos dessa ciência. Simielli (s.d., p. 27) destaca que, "para usarmos o mapa temos que conhecer essa linguagem, temos que aprender desde as séries iniciais a 'ler' através da linguagem gráfica, assim como aprendemos a nos expressar através da linguagem escrita". Ainda, complementando essa reflexão, recorremos à assertiva de Almeida e Passini (1989, p. 15), quando ressaltam que "ler mapas, portanto, significa dominar esse sistema semiótico, essa linguagem cartográfica. E preparar o aluno para essa leitura deve passar por preocupações metodológicas tão sérias quanto a de se ensinar a ler e a escrever, contar e fazer cálculos matemáticos".

Dessa maneira, entendemos que a cartografia escolar possui linguagem e metodologias específicas, sendo necessário levar o aluno à compreensão das simbologias cartográficas, por meio de sua alfabetização e/ou leiturização, sendo que o uso das novas tecnologias disponíveis e auxiliares a essa prática compõe um amparo de grande valia. 


\section{Curvas de nível}

As cartas de curvas de nível são representações gráficas da altimetria, uma representação plana que permite identificar a altitude de determinado relevo, baseando-se em pontos cotados que se unem, formando um sistema de linhas isoípsas, ou seja, aquelas linhas que unem pontos que possuem a mesma altitude.

A curva de nível é o nome utilizado para designar uma linha a qual agrupa pontos que possuem a mesma altitude ou cota. Essas linhas imaginárias, no mapa topográfico de curva de nível, são nomeadas como linhas isoípsas, sendo classificadas de altimétricas, quando na superfície, ou batimétricas, quando abaixo do nível do mar. Elas são representadas no mapa topográfico e permitem ao intérprete, ao geógrafo, ao professor e ao estudante uma visão mais abrangente da sinuosidade do terreno, possibilitando a identificação de diversas formas geomorfológicas, como vales, montanhas, níveis de inclinação, divisores de água, dentre outros aspectos, assim como a interpretação de suas informações, através de uma visão tridimensional do relevo, como observamos na Figura 1.

Figura 1 - Representação de curva de nível - Relevo fictício.

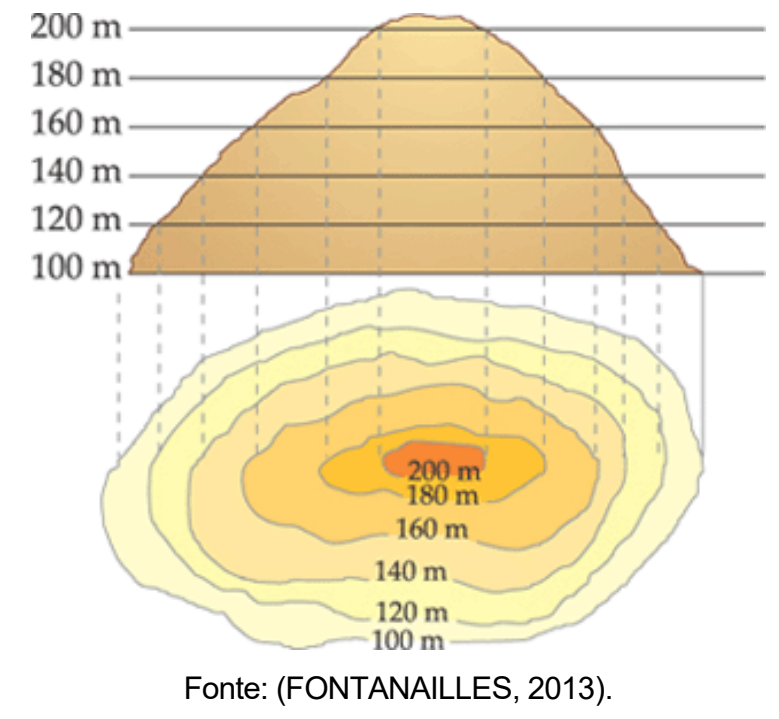

É importante destacar que as curvas de nível não se cruzam, mas, quanto maior for a declividade do relevo cartografado, mais próximas as curvas de nível aparecerão representadas. Já quanto menor for a declividade, maior será o afastamento entre elas.

A topografia interfere diretamente na ocupação do espaço geográfico. A variação da declividade do relevo pode tornar os solos mais ou menos suscetíveis à erosão ou a deslizamentos, facilitar ou dificultar a instalação de fábricas ou os processos de mecanização agrícola, favorecer ou não a construção de cidades, rodovias, ferrovias, oleodutos etc.

A partir da constatação de defasagem sobre o tema, verificada nos livros didáticos dedicados ao sexto e sétimo anos do Ensino Fundamental II, disponibilizados na instituição de ensino de execução dessa atividade e vinculados ao Programa Nacional do Livro Didático (PNLD), no arco 2017-2019, e no Caderno do Aluno, material desenvolvido pelo Governo do Estado de São Paulo, para acompanhamento por parte dos estudantes aos conteúdos trabalhados em sala de aula, e verificando a dificuldade de compreensão, quando expostos ao conteúdo, o trabalho auxiliado pelo aplicativo LandscapAR augmented reality foi desenvolvido.

\section{LANDSCAPAR E A ATIVIDADE CARTOGRÁFICA}

O aplicativo usado para a atividade proposta foi denominado, por seu idealizador, como LandscapAR augmented reality e pode ser encontrado para download na loja virtual Google Play Store, com acesso gratuito, realizado por smartphone, tablet ou computador. 
Produzido pela Weekend Labs UG, empresa de software sediada em Berlim (Alemanha), o aplicativo possui, em sua descrição na loja virtual, as informações de que foi concebido por meio da tecnologia de realidade aumentada (AR), com o objetivo de incentivar a criação artística do usuário. A descrição do produto encontrada na loja virtual Google Play Store, (2017, tradução nossa) descreve o produto como "um aplicativo com uma nova forma de realidade aumentada (AR) que convida os usuários a criar intrigantes ilhas e terrenos. Apenas esboçando as curvas de nível em uma folha de papel, será imediatamente produzida uma paisagem 3D".

Por meio do recurso da realidade aumentada, principal característica do aplicativo utilizado, o usuário tem a possibilidade de explorar o espaço tridimensional (3D). A exploração tridimensional possibilita uma maior imersão do usuário, no caso relatado, dos discentes, na atividade desenvolvida, uma vez que a simulação, manipulação e visualização dos objetos virtuais tridimensionais contribuem para a assimilação e para o saneamento de potenciais dificuldades de abstração.

A realidade aumentada possui como característica a combinação de aspectos do mundo real com o mundo virtual. Por meio dessa tecnologia, é possível que os aspectos do mundo virtual sejam transportados para o espaço real do usuário, permitindo uma interação mais natural e intuitiva. (KIRNER; KIRNER, 2011).

Além das potencialidades apontadas, as tecnologias de realidade aumentada, não tão recentes, contam com a sua popularização e facilidade de acesso em diferentes plataformas computacionais, permitindo um alcance a um número maior de usuários. Essa tecnologia ganhou força nos últimos anos ao permitir uma interface e ambiente de exploração visual interativo, misturando a percepção sensorial do ambiente real e de objetos virtuais, sendo possível interagir de forma natural, tanto com o ambiente real quanto com os objetos virtuais (PEREIRA; CENTENO, 2016). Corroborando com as ideias apresentadas, Kirner e Kirner (2011) se posicionam ao dissertar sobre a realidade aumentada:

Realidade Virtual e Aumentada são tecnologias dependentes de processamento em tempo real e, por isso, são influenciadas pela evolução da computação, tanto do ponto de vista do hardware quanto do software. Além disso, pelo fato de terem sido criadas há várias décadas, suas definições acabaram sendo modernizadas, em função de fatores mais recentes, como a multiplicidade de plataformas e a viabilização de softwares capazes de tratar elementos multissensoriais. O que antes se restringia a computadores de grande porte e a aplicações de computação gráfica, foi atualmente expandido para microcomputadores, plataformas móveis e Internet, envolvendo aplicações gráficas, sonoras, gestuais e de reação de tato e força (KIRNER; KIRNER, 2011, p.10).

O aplicativo LandscapAR augmented reality cumpre com seu objetivo ao renderizar fictícias curvas de nível, desenhadas em papel, para a realidade aumentada, gerando territórios tridimensionais que permitem uma maior imersão no estudo das características das curvas de nível, relevo, altimetria, planimetria, planialtimentria, equidistância e demais conceitos que se tornam mais próximos ao entendimento dos alunos com essa experimentação do que quando são somente trabalhados teoricamente.

Dessa maneira, para o pleno funcionamento do aplicativo, com as curvas de nível desenhadas e posicionando-se o papel em um fundo escuro, para que o papel branco possa ser identificado com maior precisão, abre-se o aplicativo no dispositivo eletrônico disponível, seleciona-se a opção "AUTO" e, com a câmera, que se ativará automaticamente, alinha-se o papel de sorte que uma borda na cor azul indique que ele esteja corretamente posicionado, como se observa na Figura 2. 


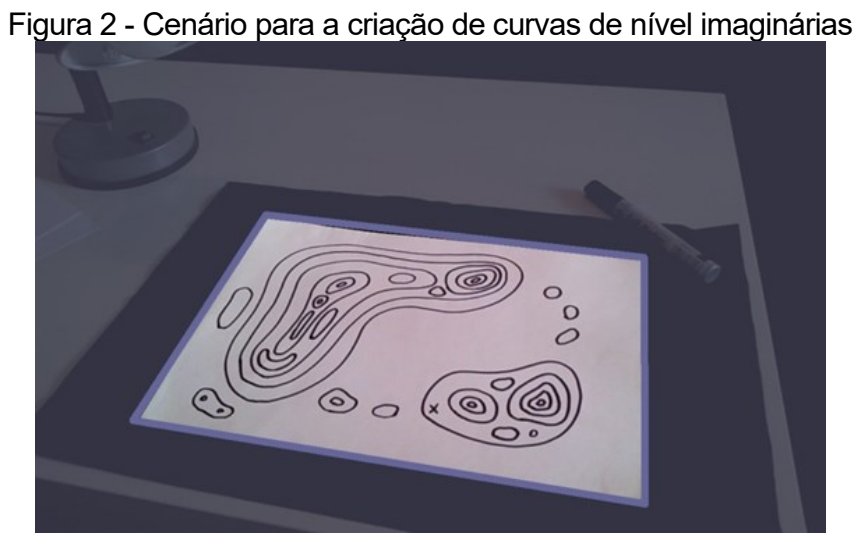

Fonte: Google Play Store (2017).

Com o papel contendo as curvas de nível devidamente enquadradas, seleciona-se, no aplicativo, a função "SCAN" e, a partir desse momento, a tecnologia de realidade aumentada será ativada e o aplicativo fará a leitura das curvas de nível, criando, na tela do próprio dispositivo eletrônico, a ilusão em três dimensões, na qual será possível observar como seria o relevo do terreno desenhado na folha de papel. A Figura 3 nos mostra essa imagem tridimensional.

Figura 3 - Imagem 3D gerada pelo aplicativo ao ler as curvas de nível.

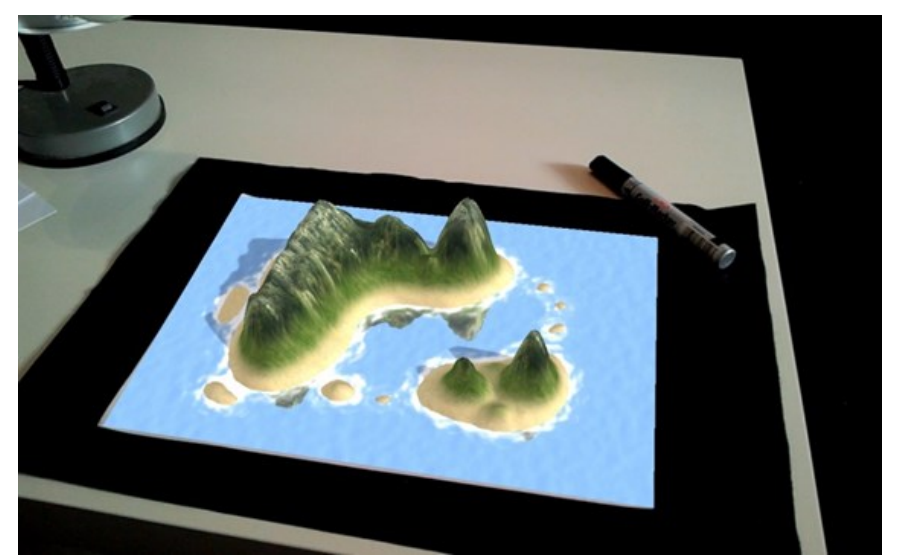

Fonte: Google Play Store (2017).

Com o uso desse aplicativo gratuito e eficiente para o objetivo de demonstrar, de forma lúdica, a função da carta de curva de nível e a formação dos relevos de terrenos, pode-se desenvolver diversas atividades, como a que será descrita a seguir.

\section{TRABALHANDO CURVAS DE NÍVEL E OS ELEMENTOS BÁSICOS DOS MAPAS}

Com o objetivo de complementar o entendimento dos estudantes acerca do conceito geográfico de curvas de nível, de oportunizar uma atividade de caráter lúdico, com o uso de materiais manuais e tecnológicos, além de proporcionar uma retomada de conceitos básicos da cartografia, a seguinte atividade foi desenvolvida no primeiro semestre do ano de 2017, com uma classe de 35 estudantes do sétimo ano do Ensino Fundamental II, de uma escola estadual localizada em um bairro de periferia de um município do interior do Estado de São Paulo com cerca de 110 mil habitantes. Foram necessários materiais como cartolina, papel sulfite, caneta hidrográfica, lápis de cor e smartphones ou tablets de estudantes e do professor, com o aplicativo aludido instalado.

Em um primeiro momento, os estudantes, organizados em grupos de quatro a cinco pessoas, utilizando caneta hidrográfica na cor preta, desenharam livremente, na folha de papel sulfite, os mapas de curva de nível conforme assimilaram a explicação já feita em aulas anteriores. Os desenhos variavam desde formas abstratas, próximas aos formatos tradicionais de mapas de curvas de nível, até mesmo a desenhos no formato de mãos, corações etc., como se nota na Figura 4. 
Figura 4 - Conjunto de curvas de nível desenhadas pelos estudantes envolvidos na atividade.

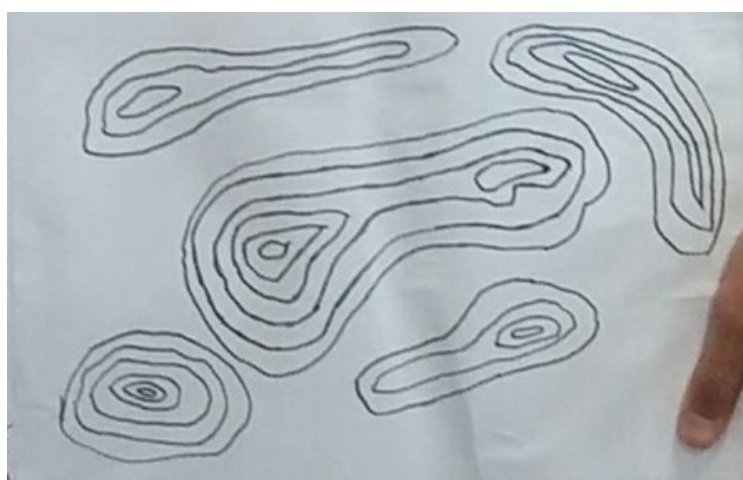

$4 a$

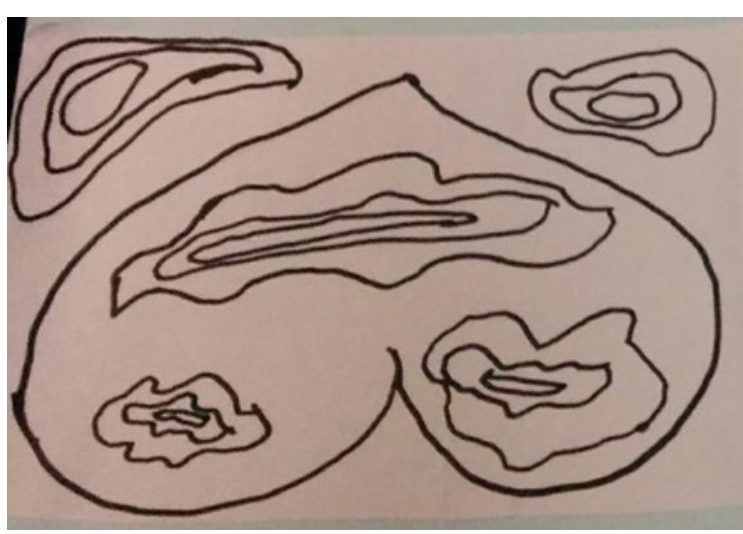

$4 \mathrm{c}$

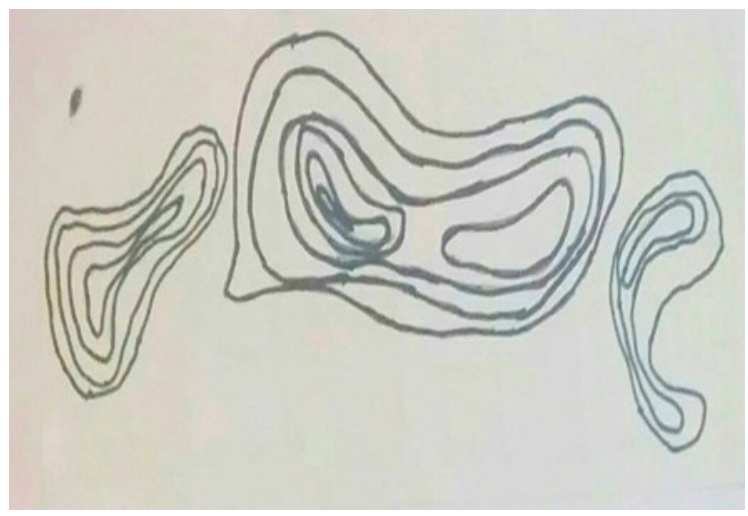

$4 e$

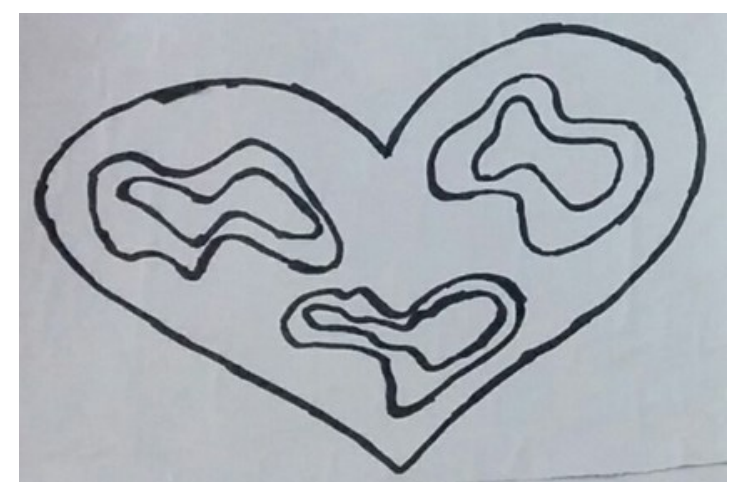

$4 b$

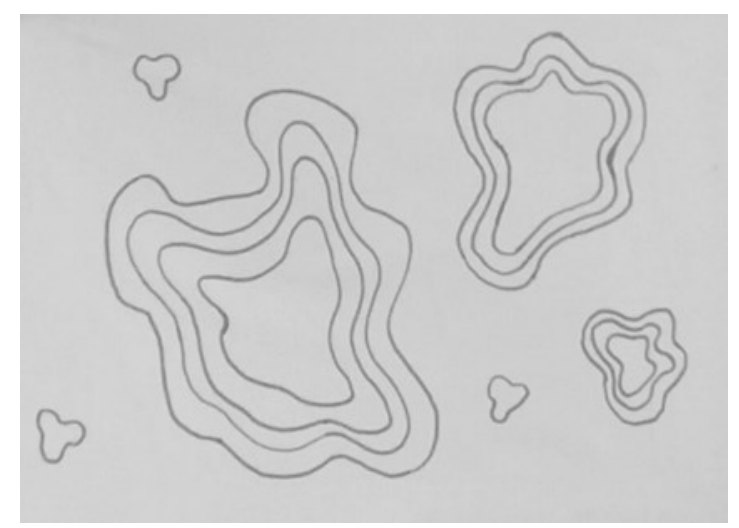

$4 d$

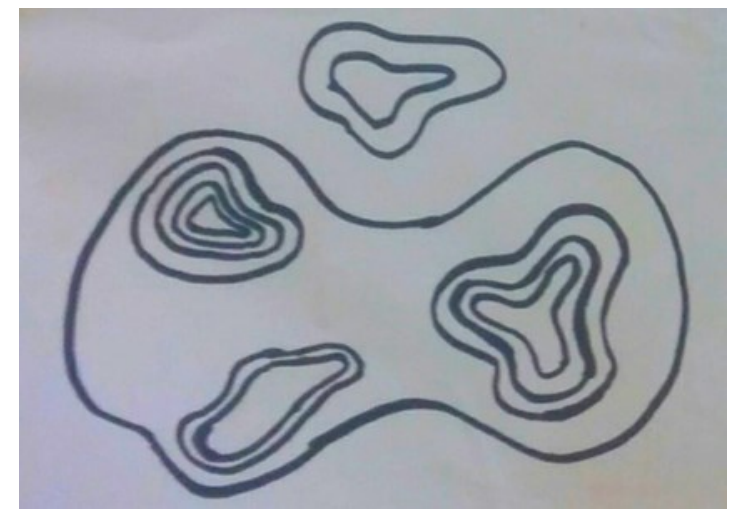

$4 f$

Fonte: Autores

Após concluírem os mapas de curva de nível, foi o momento de usar o aplicativo LandscapAR augmented reality. Para tanto, foi necessário colocar o papel sulfite com o mapa desenhado sobre uma cartolina ou papel cartão da cor preta, porque, para o pleno funcionamento do aplicativo, o papel utilizado deve estar o mais destacado possível, para a verificação da câmera do smartphone.

Ativando o aplicativo, em sua tela inicial, deve-se acionar a opção "AUTO" e posicionar a câmera de maneira que o papel, aparecendo no visor, fique com um contorno na cor azul, indicando que está no campo de visão do aparelho e corretamente selecionado. Após essa verificação, acionando o botão "SCAN", o aplicativo fará a leitura das curvas de nível e, na tela do aparelho, aparecerá o relevo que foi desenhado no papel sulfite, em um formato digitalizado. 
Esse relevo poderá ser visto de duas maneiras: a primeira, em uma visão de duas dimensões, como uma visão aérea do terreno; a outra opção, em uma visão em três dimensões (3D), ensejando uma compreensão mais clara quanto à formação do relevo e à função da carta topográfica de curvas de nível. A Figura 5 traz um exemplo de digitalização das curvas de nível.

Figura 5 - Exemplo de produção do aplicativo. A imagem 5a, desenhada por estudante, após ser submetida ao aplicativo, gerou a imagem 5al (visão aérea) e a imagem 5all (visão 3D)

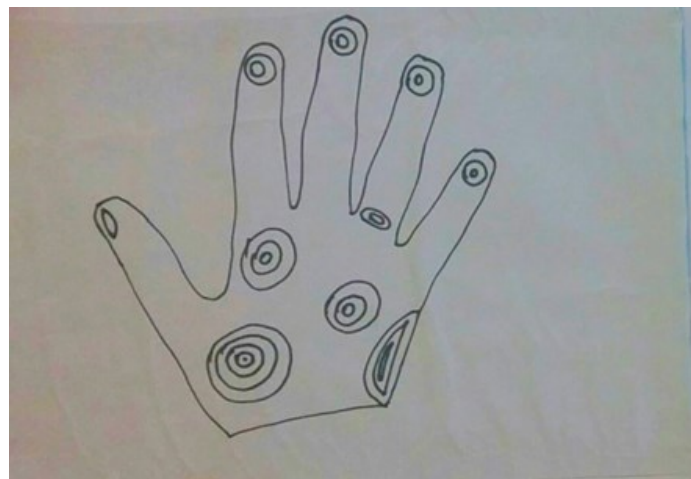

$5 a$

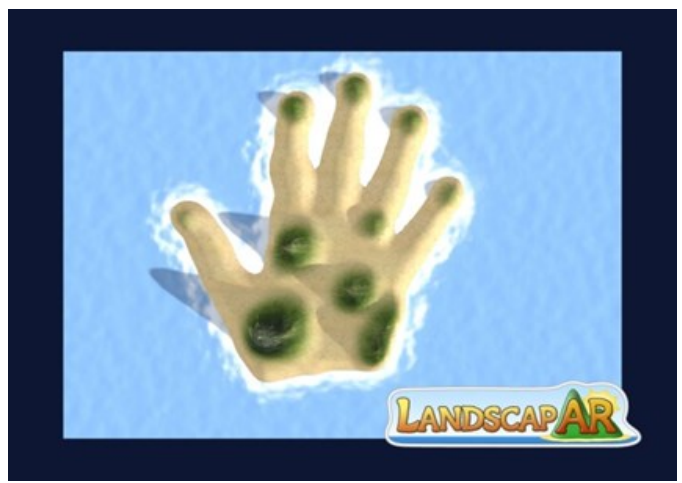

5al

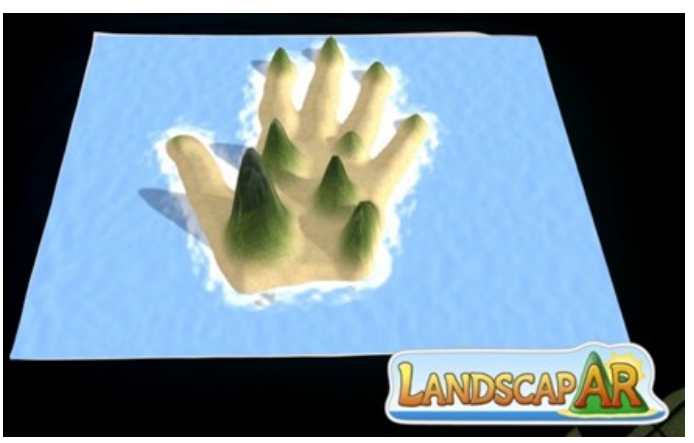

5all

Fonte: Autores

Como cada estudante do grupo de trabalho desenhou um ou mais terrenos, no aspecto de carta topográfica, os alunos tiveram que entrar em acordo para escolher aquele, gerado em visão 2D e 3D, pelo aplicativo, que mais Ihes agradou, uma vez que as opções de imagens geradas pelo aplicativo serão convertidas em arquivos de imagem, a fim de que possam ser impressos, dando continuidade à atividade.

Após imprimir as duas diferentes visões do relevo geradas pelo aplicativo, os estudantes as utilizam, juntamente com o desenho em aspecto de carta topográfica de curva de nível que produziram, e que se refere à conversão praticada pelo aplicativo, para colá-las em uma cartolina e confeccionarem um cartaz, de modo a desenvolver conceitos básicos da cartografia.

As duas imagens geradas foram preenchidas livremente pelos estudantes com elementos que Ihes convieram. Trata-se de uma oportunidade para que possam soltar a imaginação e desenhar livremente, criando um ambiente natural, uma cidade moderna, um reino medieval, elementos como rios, estradas, pontes, portos, veículos, casas, castelos, conforme a imaginação fluir. A intenção, nesse momento, é a de que criem diferentes elementos os quais farão parte da legenda, um dos preceitos básicos de um mapa. Ressalta Castellar (2005, p. 216): "A cartografia escolar tem esse papel, quando se trabalha com as formas geométricas, as cores e outros signos, criando-se condições para a identificação de símbolos que representam fenômenos geográficos e a organização de legenda".

Na Figura 6, é possível observar os dois tipos de imagens geradas já preenchidas com alguns elementos desenhados pelos estudantes, com o auxílio de lápis de cor e caneta hidrográfica. As imagens se relacionam com o mapa de curva de nível desenhado pelos estudantes e apresentados na Figura 4. Para indicar essa relação, optamos por repetir o número e a letra que já representa cada exemplo, na figura citada, seguido do algarismo romano "I", indicando a visão aérea, e do algarismo romano "Il", indicando a visão em 3D: 
Figura 6 - Imagens complementadas com uso de caneta hidrográfica e lápis de cor

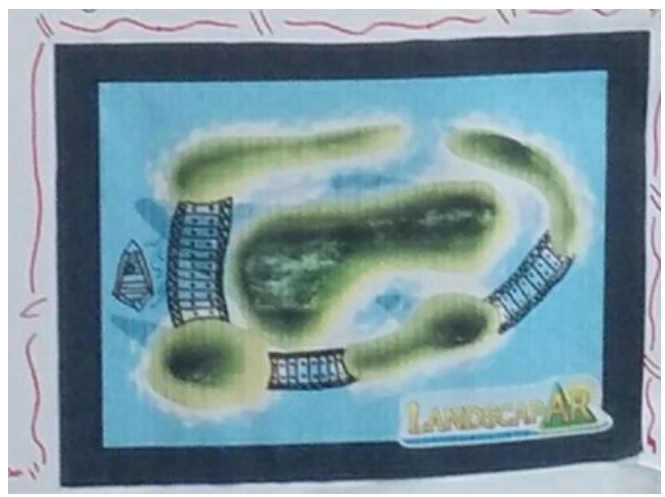

4al

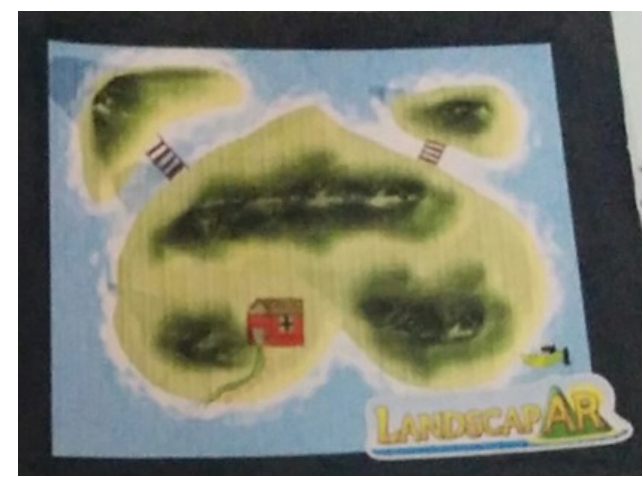

$4 \mathrm{cl}$

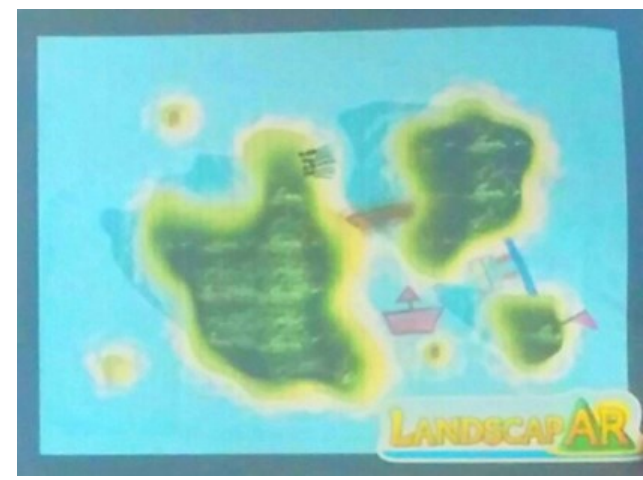

$4 d l$

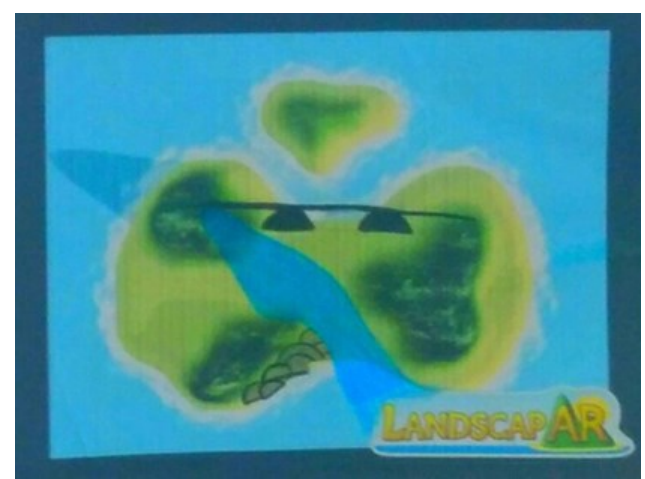

$4 \mathrm{fl}$

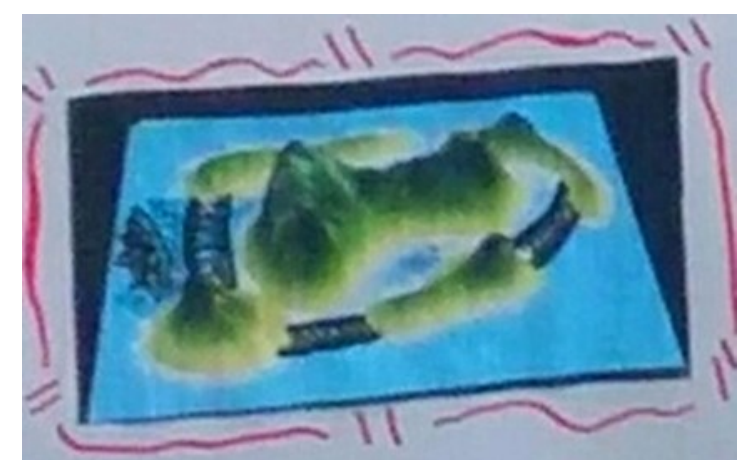

4all

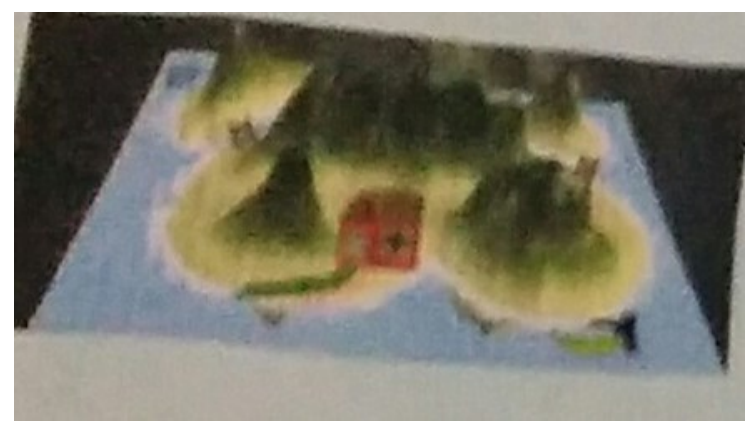

4 cll

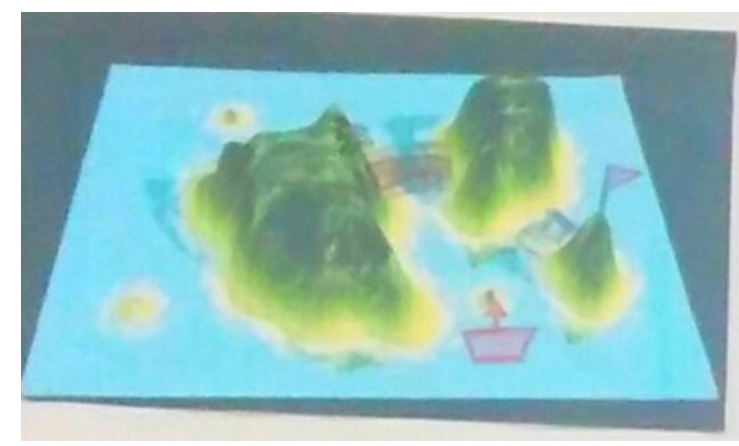

4dII

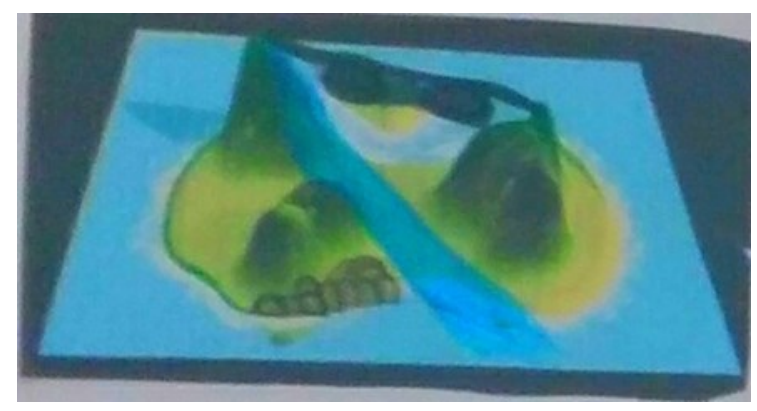

$4 f l l$

Fonte: Autores 
Após complementarem as imagens impressas com suas criações, os estudantes produziram uma legenda identificando, por meio de símbolos ou cores, cada um dos novos elementos, além dos que já tinham sido produzidos pelo aplicativo, como as montanhas, morros e vales gerados pela variação da altitude do relevo, as áreas de vegetação, de terra ou areia, e água, podendo ser interpretada como um mar ou oceano, como podemos verificar na Figura 7.

Figura 7 - Legendas produzidas pelos estudantes

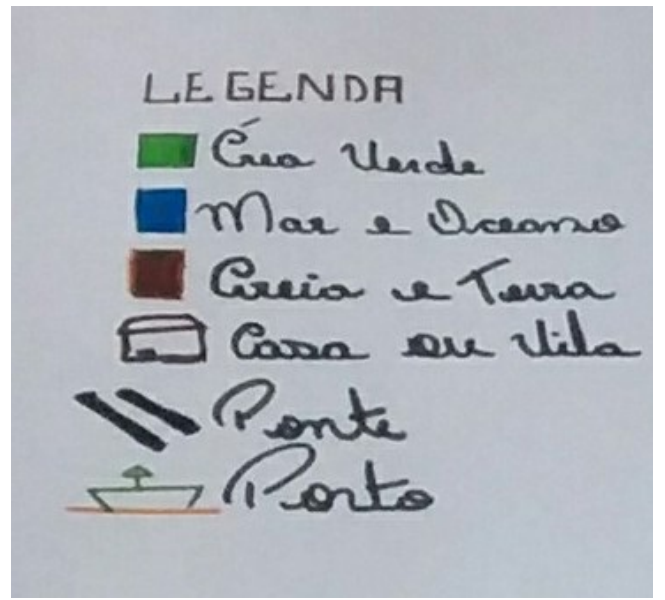

$7 a$

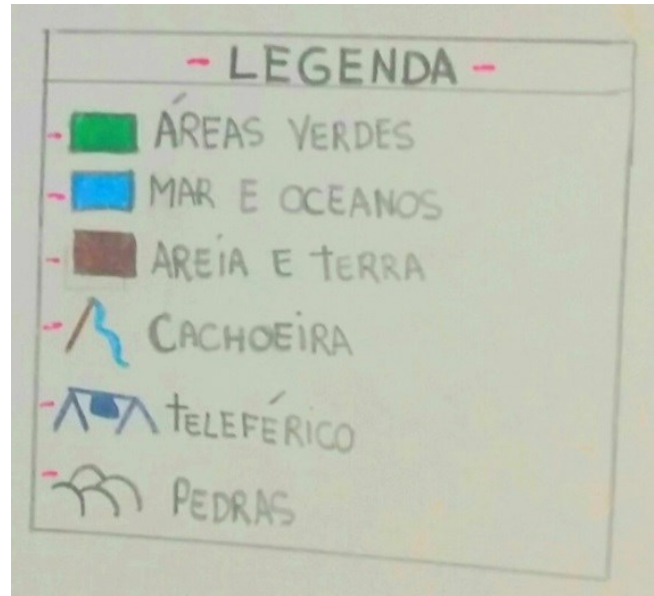

$7 b$

Fonte: Autores

O próximo passo foi a retomada do conceito de orientação, pontos cardeais e colaterais. Desse modo, os estudantes indicaram, no cartaz, o "norte geográfico" ou a representação completa da rosa dos ventos. Moreira e Sene (2014, p.17) assinalam: "A rosa dos ventos possibilita encontrar a direção de qualquer ponto da linha do horizonte (numa abrangência de $360^{\circ}$ ). O nome foi criado na época da expansão marítima (século XV) por navegadores do mar Mediterrâneo em associação aos ventos que impulsionavam suas embarcações".

Assim, os estudantes posicionaram uma rosa dos ventos na cartolina ou na própria imagem gerada pelo aplicativo, apontando a maneira correta com que se deveria analisar o terreno criado. A escolha do norte geográfico foi feita pelos alunos, uma vez que se trata de terrenos fictícios e de autoria dos mesmos. A Figura 8 retrata esse momento da atividade.

Figura 8 - Rosa dos ventos produzida pelos estudantes

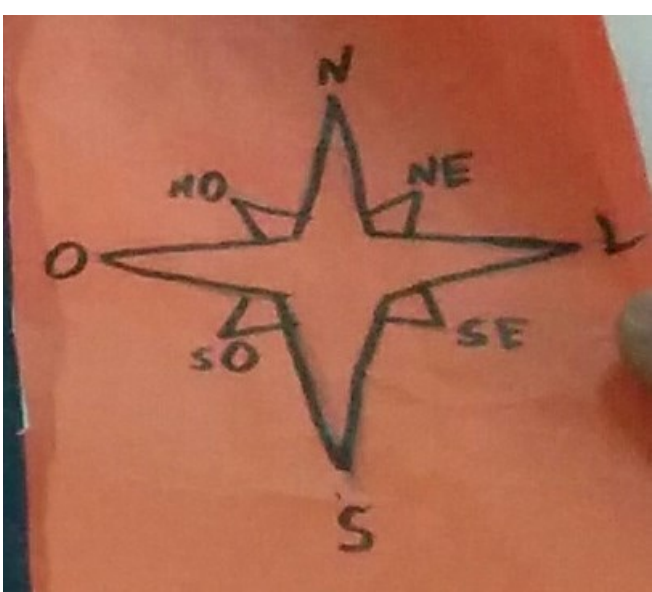

$8 a$

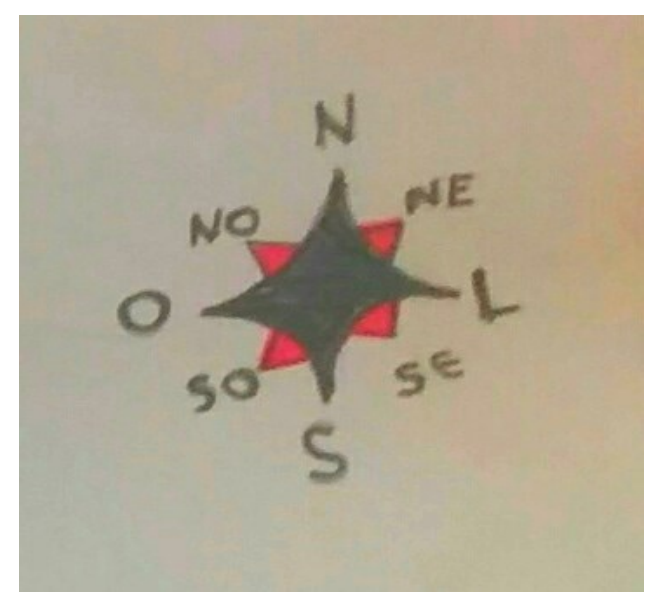

$8 b$

Fonte: Autores 
Quanto à escala cartográfica, outro elemento básico de um mapa, a atividade proposta não obedeceu a métricas exatas, uma vez que os terrenos são fictícios, criados pelos próprios estudantes, sem referência alguma à realidade. Assim, o emprego da escala cumpre seu objetivo para alunos do sétimo ano do Ensino Fundamental II, ao contribuir para que relembrem seu conceito, importância como requisito básico de um mapa, e sua utilidade, além de suas formas diferentes de se expressar, sendo, portanto, orientados apenas a recordar os dois tipos de escalas cartográficas existentes e usados em mapas, ou seja, a escala numérica e a escala gráfica, como demonstra a Figura 9, representando, em seu trabalho, aquela que mais Ihes agrada visualmente, para o resultado final de criação.

Figura 9 - Escala gráfica fictícia produzida pelos estudantes

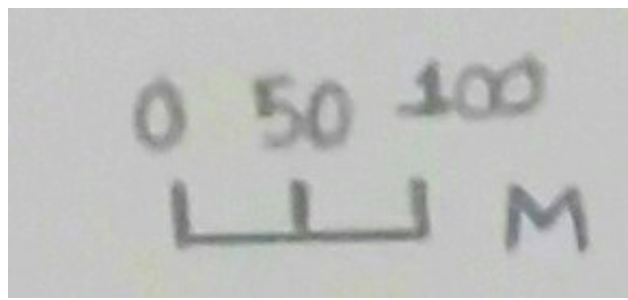

Fonte: Autores

Encerrando esse momento de retomada de conceitos da cartografia, os estudantes nomearam seu terreno, deram-lhe um título, elemento esse que também faz parte dos preceitos básicos de um mapa. $O$ título, a cargo dos estudantes, foi mais uma oportunidade para agirem de forma criativa, como pode ser notado na Figura 10.

Figura 10 - Títulos criados pelos estudantes

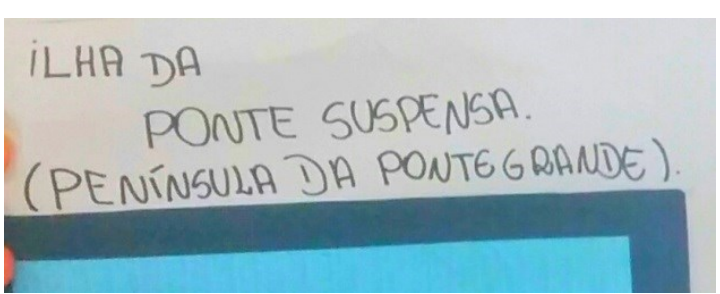

$10 a$

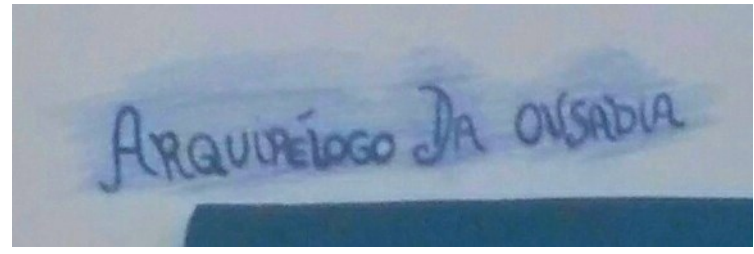

$10 \mathrm{~b}$

Fonte: Autores

Seguindo os passos descritos anteriormente, os estudantes puderam produzir seu material final. Os cartazes confeccionados receberam o nome da atividade desenvolvida, qual seja, "Trabalhando Curvas de Nível: Mapa e Aplicativo". Esses cartazes contavam com o mapa de curva de nível desenhado por eles, com as duas diferentes perspectivas visuais produzidas pelo aplicativo e preenchidas livremente com iluminuras pelos estudantes, além dos requisitos básicos para a produção de um mapa - título, legenda, orientação e escala - estudados durante o sétimo ano do Ensino Fundamental II. A Figura 11 traz exemplos de resultados finais parciais ou conclusos. 
Figura 11 - Produto final desenvolvido pelos estudantes com a atividade

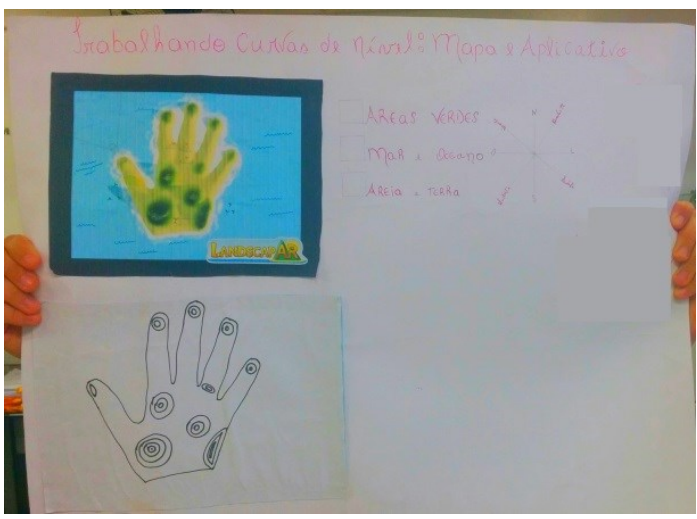

$11 \mathrm{a}$

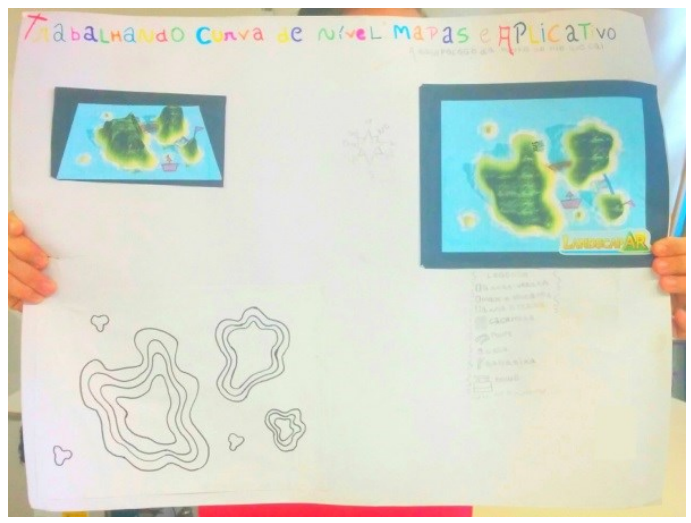

$11 \mathrm{c}$

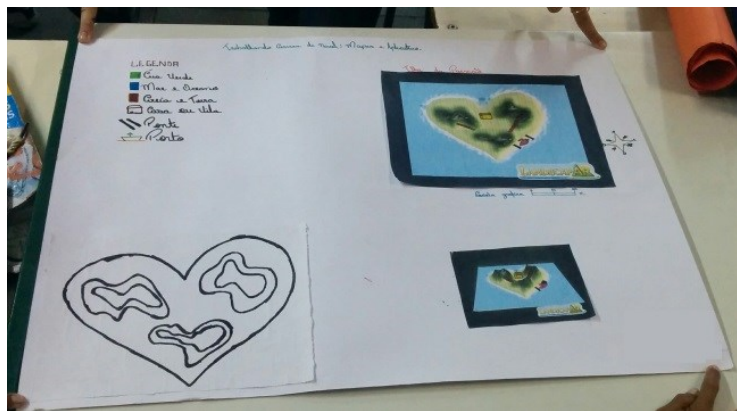

$11 \mathrm{e}$

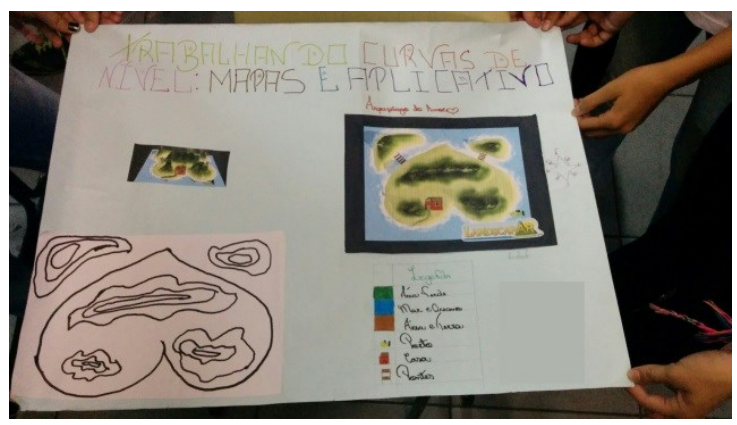

$11 \mathrm{~g}$

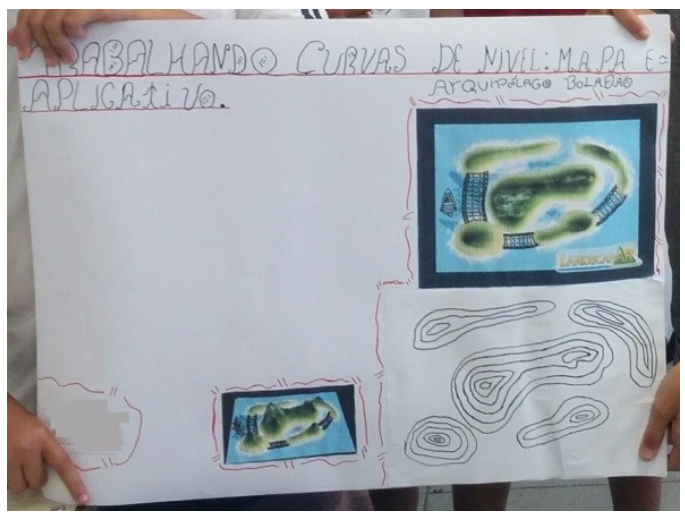

$11 b$

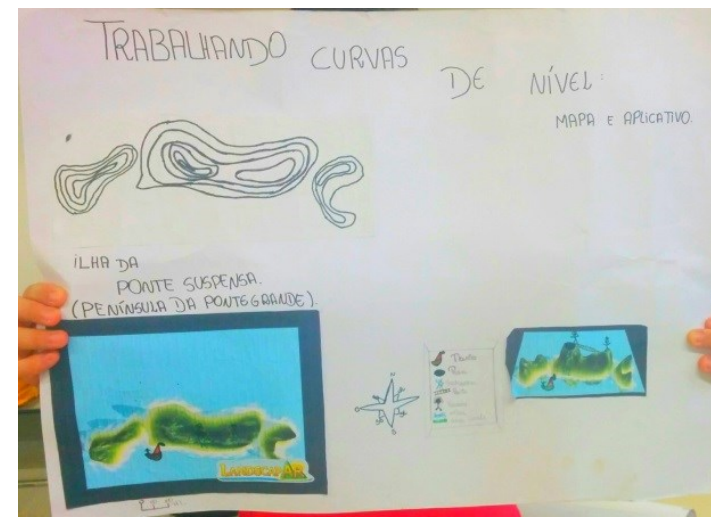

$11 d$

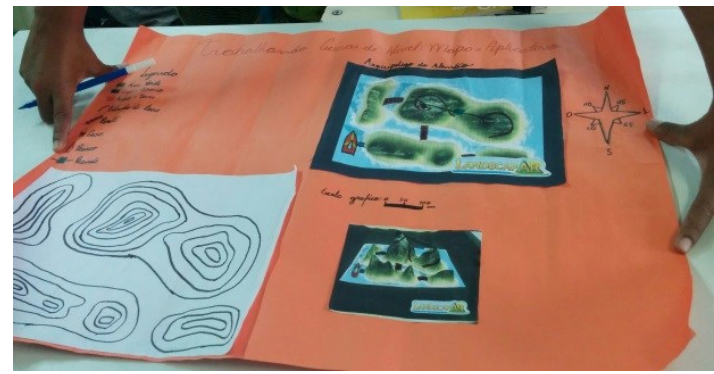

$11 f$

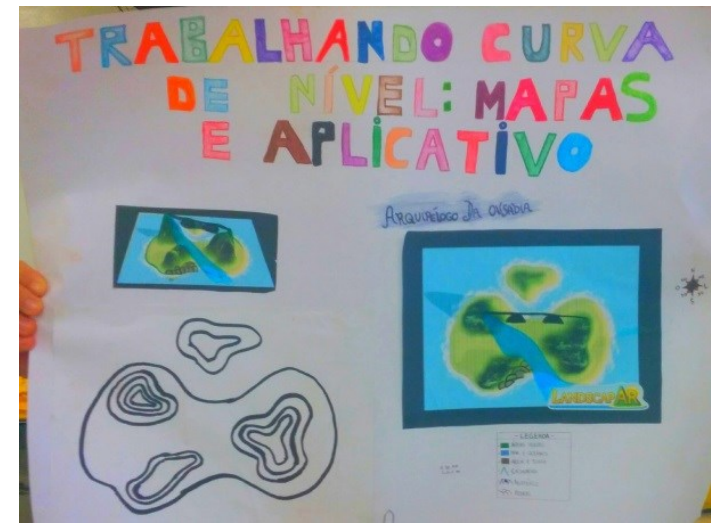

$11 \mathrm{~h}$

Fonte: Autores

v. 22 , n. 79

Fev/2020

p. $39-55$

Página 52 
A prática descrita foi planejada e realizada no tempo correspondente a quatro aulas, sendo que a primeira aula foi dedicada à explicação de novos conceitos cartográficos, como o conceito de curva de nível, e a retomada de conceitos já trabalhados, como título, orientação, escala e legenda, os quais envolviam a produção dos mapas de curva de nível.

A segunda aula foi direcionada à produção das curvas de nível pelos alunos e à digitalização de suas criações, com o uso do aplicativo LandscapAR augmented reality. Entre a segunda e a terceira aula, com o auxílio da coordenação pedagógica da escola, foi feita a impressão em papel sulfite das diferentes visões, em duas e três dimensões, dos territórios produzidos pelos alunos. A terceira aula foi pautada pela criatividade dos alunos para preencherem os espaços criados por eles com novos elementos e, por fim, na quarta aula, foi confeccionado o cartaz final com a colagem dos três mapas (curva de nível, visão 2D e visão 3D) e os detalhes finais, como a escala, a legenda, o título e a orientação.

Dessa forma, com o desenvolvimento da atividade proposta, além de apreenderem e se aprofundarem em um novo conceito, no caso em tela, o conceito de curvas de nível, os estudantes tiveram a oportunidade de retomar concepções já estudadas, durante o ano letivo, praticar uma atividade lúdica, prazerosa para os mesmos, e por que não, para o professor, além de atrelar a tecnologia ao ensino-aprendizagem.

\section{CONSIDERAÇÕES FINAIS}

Em tempos de processo de ensino-aprendizagem pautado por projetos pedagógicos e uso de tecnologias de comunicação e informação visual e sonora, a prática docente requer estudos e discussões cada vez mais aprofundados sobre as referidas temáticas. Apesar do incentivo, ainda que incipiente, encontrado em alguns discursos acadêmicos e administrativos, em propagandas sobre políticas educacionais, a fim de que se estabeleçam esses usos, em sala de aula, muitas vezes tais atitudes visam apenas à necessidade de números para compor objetivos institucionais, não oferecendo aos profissionais da educação uma formação continuada suficiente para que possam, de fato, fazer uso desses instrumentos tecnológicos.

Nesse seguimento, muitos docentes não possuem formação adequada voltada para o uso de tecnologias de informação e comunicação (TIC), em sua prática. Além de outros obstáculos que dificultam o uso corrente desses recursos tecnológicos, no ambiente escolar, como a falta de materiais, de verbas e de incentivo advindo dos membros hierarquicamente superiores dentro das escolas, ainda há certa resistência, visto que muitos relacionam o uso da tecnologia a um meio para que estudantes e professores não cumpram com o objetivo de aprendizagem, nas aulas, não enxergando a tecnologia como um material de apoio ao ensino. Nesse sentido, assentimos com a fala de Imbernón (2010):

Para que o uso das TIC signifique uma transformação educativa que se transforme em melhora, muitas coisas terão que mudar. Muitas estão nas mãos dos próprios professores, que terão que redesenhar seu papel e sua responsabilidade na escola atual. Mas outras tantas escapam de seu controle e se inscrevem na esfera da direção da escola, da administração e da própria sociedade. (IMBERNÓN, 2010, p. 36).

Isso posto, uma das discussões aqui levantadas leva em conta a geração de estudantes que ocupam as carteiras das escolas contemporâneas. Como vimos, seguindo as classificações de White e Cornu (2011) e as reflexões do professor Cassany (2017), chega-se à conclusão de que a atual geração de estudantes seria classificada, quase que totalmente, como "residentes digitais", ou seja, a geração que nasce e vive em um contexto permeado de tecnologia, jovens que se mantêm conectados o dia todo, seja por meio de um computador fixo, seja notebook, smartphone ou tablets, em casa, no trabalho ou na rua. Em face desse contexto, faz-se necessário que o professor cumpra seu papel mediador na relação do estudante com o meio digital de aprendizagem, obtendo o conhecimento específico para tal e possibilitando a construção de um sujeito cada vez mais crítico e capaz de elaborar níveis de compreensão mais substanciais. Ademais, é imperioso que o poder público tome para si a responsabilidade de valorização profissional, a fim de que atinjam esses objetivos. Um debate extenso e que merece maior atenção e aprofundamento.

Os trechos do currículo-base oficial do Estado de São Paulo para os anos iniciais e anos finais do Ensino Fundamental e Ensino Médio, elaborado no ano de 2008, pela Secretaria da Educação do Estado de São Paulo, aqui apresentados, mostram que, no ensino de geografia, a leitura e a interpretação de mapas é preceito básico que deve ser desenvolvido, e os mapas de curva de nível estão inseridos nesse contexto. Por meio das aulas desenvolvidas, principalmente durante as explanações teóricas e retirada de dúvidas levantadas pelos estudantes, foi possível observar que a dificuldade na compreensão do conceito de curvas de nível é traço comum à maior parte dos estudantes, na faixa etária que compõe o sétimo ano, 
entre 12 e 13 anos, uma vez que, seguindo o currículo oficial do Estado de São Paulo, é nesse momento que tal conceito é introduzido ao estudante, voltando a ser elucidado em anos posteriores.

Ao executar a atividade aqui descrita, conclui-se que o aplicativo LandscapAR augmented reality possui uma funcionalidade simples, sendo de fácil acesso, uma vez que é um aplicativo gratuito, cumpre com o objetivo de ser uma ferramenta lúdica para a confecção de territórios, a partir do esboço de curvas de nível, podendo funcionar como um instrumento auxiliar para o desenvolvimento do conceito, em sala de aula.

Os estudantes demonstraram um interesse pelo assunto claramente potencializado pelo uso dos smartphones e do aplicativo. Muitos empregaram o aplicativo em suas residências, após o desenvolvimento da atividade, para continuar a brincar e aprender ao mesmo tempo, exibindo suas novas criações em aulas posteriores.

A presença de uma nova tecnologia de informação e comunicação, em meio às aulas de geografia, foi capaz de despertar o interesse dos estudantes pelo estudo proposto, em uma dimensão superior à comum apresentada pela sala, tornando o processo ensino-aprendizagem mais dinâmico e condizente com a velocidade de informações recebidas pelos mesmos, em seu cotidiano. Uma reorganização do espaço-tempo, da dinâmica didática e da introdução de um meio digital torna-se uma nova estratégia de ensino-aprendizagem, conforme já elucidado por Almeida, 2002, supracitado na introdução deste artigo.

O fato de desenvolverem um trabalho em grupo, no qual fizeram uso de materiais e técnicas diversas, também se mostrou de grande valia para o processo ensino-aprendizagem, fazendo com que recuperassem conceitos já trabalhados em momentos anteriores, como os requisitos básicos de um mapa - título, orientação, legenda e escala.

Por fim, podemos garantir que a atividade desenvolvida, como um todo, e dentro do contexto de realidade no qual os alunos envolvidos estão inseridos, em que muitos não acatam as atividades propostas pelos professores, não realizam tarefas ou participam ativamente das aulas, revelou-se efetiva, satisfatória e contribuinte para uma melhor compreensão, por parte dos discentes, do conceito de curva de nível, para o desenvolvimento de habilidades de escrita e processo criativo, além de proporcionar momentos de sociabilização entre estudantes, entre estudantes e professor - e, por que não, momentos de diversão e, principalmente, aprendizagem mútua.

\section{REFERÊNCIAS}

ALMEIDA, M. E. B. Escola em mudança: experiências em construção e redes colaborativas de aprendizagem. In: ALONSO, M.; ALMEIDA, M. E. B.; MASETTO, M. T.; MORAN, J. M.; VIEIRA, A. Formação de gestores escolares para utilização de tecnologias de informação e comunicação. Brasília: Secretaria de Educação a Distância, 2002. p. 41-62,

ALMEIDA, R. D. de; PASSINI, E. Y. O espaço geográfico: ensino e representação. São Paulo: Contexto, 1989.

BRABANT, J. Crise da geografia, crise da escola. In: Para onde vai o ensino de geografia? 10. ed., 1. reimpr. São Paulo: Contexto, 2017. p.15-23.

CASSANY, D. Letramento crítico; Identidades y culturas digitales; Ortografías y alfabetos. Notas de aula, Programa de Pós-Graduação em Ensino e Processos Formativos, Universidade Estadual Paulista, São José do Rio Preto, 2017.

CASTELLAR, S. M. V. Educação Geográfica: A psicogenética e o conhecimento escolar. Cadernos Cedes, Campinas, v. 25, n. 66, p. 209-225, maio./ago. 2005. Disponível em: http://www.cedes.unicamp.br. Acesso em: 30 de janeiro de 2020. https://doi.org/10.1590/S0101-32622005000200005

FONTANAILLES, G. Cartografia: Escala e Curva de Nível. 2013. Disponível em: http://geografalando.blogspot.com.br/2013/03/cartografia-escala-e-curvas-de-nivel.html. Acesso em: 30 de janeiro de 2020.

GOOGLE PLAY STORE. LandscapAR augmented reality. Disponível em: https://play.google.com/store/apps/details?id=de.berlin.reality.augmented.landscapar\&hl=pt_BR. Acesso em: 23 de novembro de 2017. 
IBGE - Instituto Brasileiro de Geografia e Estatística. Departamento de Cartografia. Nocões Básicas de Cartografia. Rio de Janeiro: IBGE, 1999. Disponível em: https://biblioteca.ibge.gov.br/index.php/ biblioteca-catalogo?view $=$ detalhes\&id=281661. Acesso em: 30 de janeiro de 2020.

IMBERNÓN, F. Formação docente e profissional: formar-se para a mudança e a incerteza. 7. ed. São Paulo: Cortez, 2010.

KATUTA, A. M., SOUZA, J. G. DE. Geografia e conhecimentos cartográficos. A cartografia no movimento de renovação da geografia brasileira e a importância do uso de mapas. São Paulo: Editores UNESP, 2001.

KIRNER, C.; KIRNER, T. G. Evolução e Tendências da Realidade Virtual e da Realidade Aumentada. In: SYMPOSIUM ON VIRTUAL REALITY AND AUGMENTED REALITY, 13., 2011, Uberlândia-MG. Anais [...] Uberlândia, MG: SBC, 2011. cap. 01, p. 10-25. Tema: Realidade Virtual e Aumentada: Aplicações e Tendências. Disponível em: http://www.de.ufpb.br/ labteve/publi/2011_svrps.pdf Acesso em: 01 de junho de 2020.

MOREIRA, J. C.; SENE, E. Projeto Múltiplo: geografia, 1. ed. São Paulo: Scipione, 2014.

OLIVEIRA. A. G. O conhecimento geográfico e a representação cartográfica: recortes para uma análise. In: ENCONTRO REGIONAL DE ESTUDOS GEOGRÁFICOS, X, 2009, Campina Grande. Anais [...] Campina Grande: Realize, 2009.

PEREIRA, G. H.A.; CENTENO, J. A. S., 2016. O Uso de Realidade Aumentada para a Cartografia: Uma Nova Forma de Interagir com Mapas e Dados Geográficos. Revista Brasileira de Cartografia, Vol. $68, \mathrm{~N}^{\circ} 4$, pp. 685-694.

PRENSKY, M. Digital Natives, Digital Immigrants. On the Horizon, Minneapolis, EUA, v. 9, n. 5, out. 2001. Disponivel em: https://www.marcprensky.com/writing/Prensky\%20-\%20Digital\%20Natives,\%20 Digital\%20lmmigrants\%20-\%20Part1.pdf. Acesso em: 14 de abril de 2017.

SÃO PAULO (Estado). SEE/SP. Currículo do Estado de São Paulo: Ciências Humanas e suas Tecnologias. Secretaria da Educação; coordenação geral, Maria Inês Fini; coordenação de área, Paulo Miceli. 1. ed. atual. São Paulo: SEE, 2012.

SIMIELLI, M. E. R. Cartografia no ensino fundamental e médio. In: A geografia na sala de aula. 8. ed., 3. reimpr. São Paulo: Contexto, 2010.

SIMIELLI, M. E. R. O uso de plantas e mapas na escola de $1^{\circ} \mathrm{grau}$ - ênfase para as séries iniciais. São Paulo: AGB - s.d. p. 27-40 (Projeto "O Ensino da cidade de São Paulo").

SOUSA. A. B. S. et al. A construção de representações cartográficas a partir do uso de imagens de satélite em sala de aula. In: ENCONTRO REGIONAL DE ESTUDOS GEOGRÁFICOS, X, 2009, Campina Grande. Anais [...] Campina Grande: Realize, 2009.

VESENTINI, J. W. Realidades e perspectivas do ensino de geografia no Brasil. Campinas: Papirus, 2004.

WHITE, D. S.; CORNU, A. L. Visitors and residents: Towards a new typology for online engagement. First Monday Peer-Reviewed Journal On The Internet, Chicago, EUA, v. 16, n. 9, set. 2011. Disponível em: http://firstmonday.org/ojs/index.php/fm/article/viewArticle/3171/309. Acesso em: 14 de abril de 2017.

Recebido em: 28/03/2020

Aceito para publicação em: 03/07/2020 